\title{
TEST FIELD FOR LV DISTRIBUTION SYSTEMS
}

\author{
Jan Desmet \\ Howest - UGent - Belgium \\ jan.desmet@howest.be
}

\author{
Bart Verhelst \\ Howest - UGent - Belgium \\ bart.verhelst@howest.be
}

\author{
Lieven Vandevelde \\ UGent - Belgium \\ lieven.vandevelde@ugent.be
}

\author{
Colin Debruyne \\ Howest - UGent - Belgium \\ colin.debruyne@ howest.be
}

\begin{abstract}
Detailed analysis of an actual Low Voltage distribution grid is often difficult due to practical considerations. Designers generally use simulation tools to predict the behavior of the distribution grid, although parasitic effects are hard to predict and even harder to model accurately. In this paper an actual, but free programmable, distribution grid is presented which enables detailed analysis of nearly all the electrical parameters of a residential distribution grid. Although this paper focusses on the design of this demonstrator project, some suggestions to future research are indicated.
\end{abstract}

\section{INTRODUCTION}

The current public low voltage distribution grid has been designed unidirectional, from a single point of supply to the different loads. Recently the distribution grid has been subjected to a lot of new evolutions to which it was not originally designed. From harmonic current injection over distributed generation (DG) up to power line communication (PLC) and Demand Side Management (DSM), adding significant stress to the grid. Introduction of the smart grid will even further expand the functionalities of the distribution grid in reference to which it was originally designed.

Although several studies have indicated fundamental differences between simulation and actual implementation, usually most studies are performed by simulation because of practical actual grid behavior is hard to obtain. The low voltage distribution grid, and the connected equipment, has not been designed to be flexible. Consequently, testing to extreme values of voltages, frequencies or currents is out of the question.

Most of the time, simulation models are not adequate and do neglect parasitic effects, although these effects have proven in some cases to be equally important. This paper presents the realization of a flexible test platform designed for relevant power with respect to the real low voltage distribution grid. It can easily be reconfigured to different distribution topologies, different types of house hold power connections, different loads, DG injection reconfigurable in both locations and power, as it is also equipped with a programmable supply system of 240kVA.
This paper will begin with an extensive analysis of the technical design parameters and calculations often used to design a public distribution grid, After studying the current grid, the design process of a flexible transparent test grid is elucidated.

\section{DESIGN PROCES}

\section{Evaluation of the current distribution grid}

Both the applied voltage, the practical layout as the protection mechanisms used, differ significantly if European power grids are compared to grids in North America. This paper focuses on European grids but [1] is stated as a reference for the study of North American Power Grids.

Medium voltage grids, with a voltage range of $70 \mathrm{kV}$ to $\pm 10 \mathrm{kV}$ are outside the scope of the research. If Low Voltage grids $(<1 \mathrm{kV})$ are considered, these are predominantly present within industrial / large building power grids and for public distribution.

Sites which have the MV to LV transformer on site, usually industrial or large buildings, are not envisioned. First of all, these sites are individually designed towards safety and reliability. [2] Secondly, if DG is implemented in these sites, this is generally of significant magnitude and are often directly coupled to the MV grid.

Compared to the specific design in case of industrial power grids, public LV grids have a fairly similar design. Although some minor differences are present between the densely populated urban grids and the more spread rural grids.

All public LV grids are designed from a single point of supply, generally a MV to LV transformer. The upstream MV grid rated short circuit power varies between 180 MVA, which is considered a "weak" grid, to the "stronger" $500 \mathrm{MVA}$. The rated power of the MV/LV transformer is in average about $630 \mathrm{kVA}$ and, because of the transformation, the MV grid short circuit power is generally of little to no significance.

From this transformer, several seperate feeders depart. These feeders are commonly placed in a pure radial configuration, as this largely simplifies the network in terms of both power flow and consequently fault 
behaviour. For densely populated areas, feeders are likely to be placed underground and EAXVB $4 \times 150 \mathrm{~mm}^{2}$ with maximum length of $<1 \mathrm{~km}$ are often installed. For rural areas the feeders are preferably pole mounted, because of the reduced cost, and are BXB $3 \times 95 \mathrm{~mm}^{2}$ with a reduced neutral conductor section of $54 \mathrm{~mm}^{2}$.

Historically, different Distribution Network Operators (DNO) installed slightly different transformers. Although the liberalisation of the electricity market resulted in more uniformisation. The supply voltage is generally supplied by a DY transformer with a resulting voltage of $230 \mathrm{~V} / 400 \mathrm{~V}$, although older DD transformers are still in use which supply $230 \mathrm{~V}$.

Upon the feeders the residential sites are connected. Normally residential nodes are limited in amount of capacity, a general value is a limit of approx. 40A per node. However, do to the spread of consumption within a certain timeframe, a lot of models have been suggested which calculate the coincidence factor.

According to the model of Rusck, [12] the coincide factor $g_{n}$ can be calculated according to Eq.1., in which $n$ is the number of nodes and $g_{\infty}$ the coincidence factor for an infinite number of users.

$$
g_{n}=g_{\infty}+\left(1-g_{\infty}\right) \frac{1}{\sqrt{n}}
$$

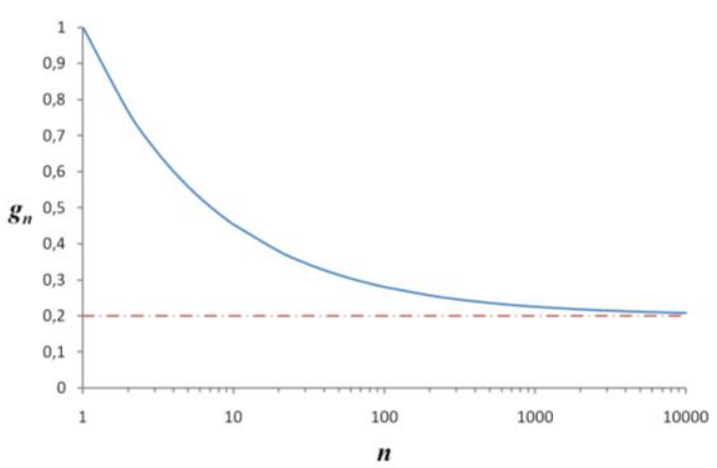

Fig. 1: coincidence according to the model of Rusk

According to survey from Belgian DNO the coincidence for residential grids is in between the 0.2 en 0.4 . This implies that approximately 20 nodes per feeder are present.

As the physical layout of a "generalized" public distribution grid is now known, the goal is to obtain a similar physical programmable grid, both in supply conditions, physical layout as in flexible load/DG.

\section{Designing the demonstrator}

A schematic overview of the designed grid is illustrated in Fig. 2. As the supply voltage can contain both harmonic distortion and unbalance, a free programmable $240 \mathrm{KVA}$ power source is used as supply system. The frequency domain is from DC to $5 \mathrm{kHz}$, with a $50 \mathrm{kHz}$ small signal bandwidth. The supply voltage also can be switched to the public distribution grid if larger power is needed. (Fig. 4)

Distribution grids are designed to specific needs, which differ between locations. Therefore a three segmented reconfigurable distribution feeder of the type EAXVB $150 \mathrm{~mm}^{2}$ has been installed, allowing up to 7 distinctive topologies. This enables testing of radial, ring and open ring nets, with varying feeder lengths up to $600 \mathrm{~m}$.

Eighteen connection nodes are made along the feeder, representing residential Points of Connection. Often the POC's connection from the public feeder to the feeder is neglected, although the reduced section of this connection can significantly influence the voltage. Therefore three connections for each node are possible, each have a cable length of $25 \mathrm{~m}$, and with different cross sections, namely $10 \mathrm{~mm}^{2}, 16 \mathrm{~mm}^{2}$ and $25 \mathrm{~mm}^{2}$.

New grid configurations are generally fed by a $230 \mathrm{~V} / 400 \mathrm{~V}$ network, although older grids are supplied from a three phase $230 \mathrm{~V}$ network. The complete network is fully reconfigurable between these two topologies. This has its implications within each node.

Also 10 inverters of $1 \mathrm{~kW}$ solar power can be connected anywhere within this grid.

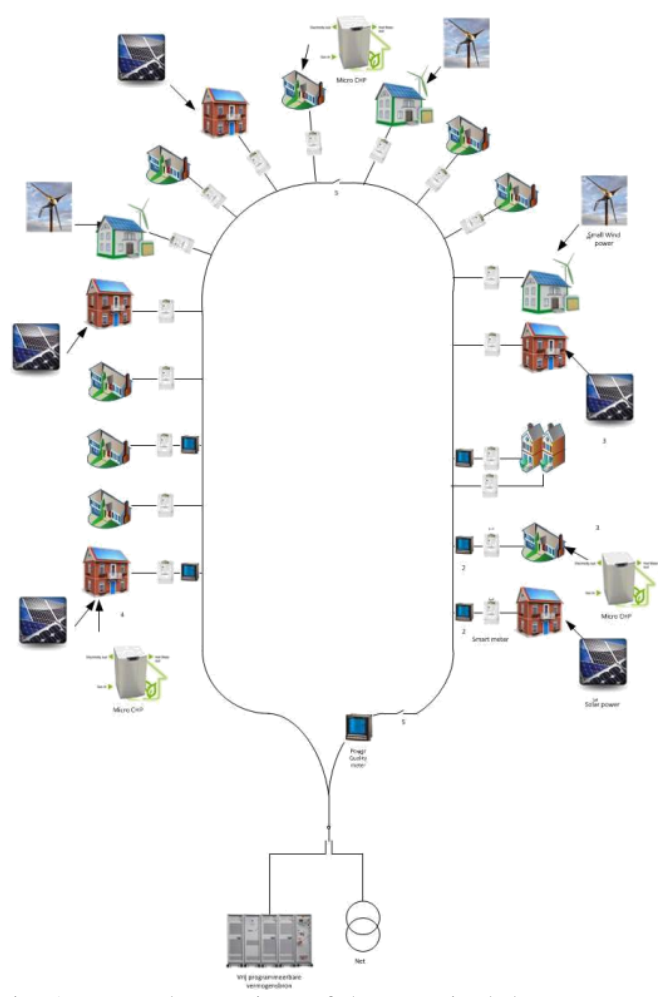

Fig. 2: general overview of the practical demonstrator 
At the moment of publication, the proposed test facility is already in its testing phase. Each cabined presented in Fig. 3 represents 2 POCs. In Fig. 5 the practical demonstrator is being illustrated.

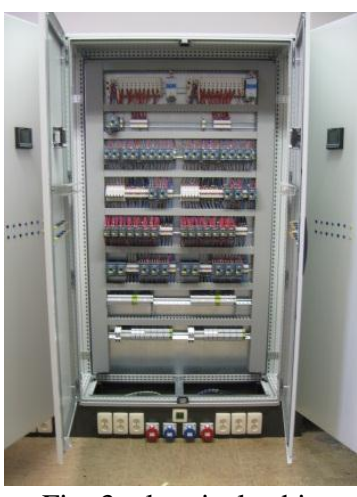

Fig. 3: electrical cabinet

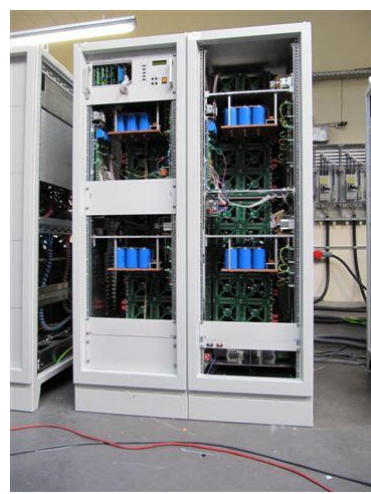

Fig. 4: single power stage of the three phase $240 \mathrm{KVA}$ supply

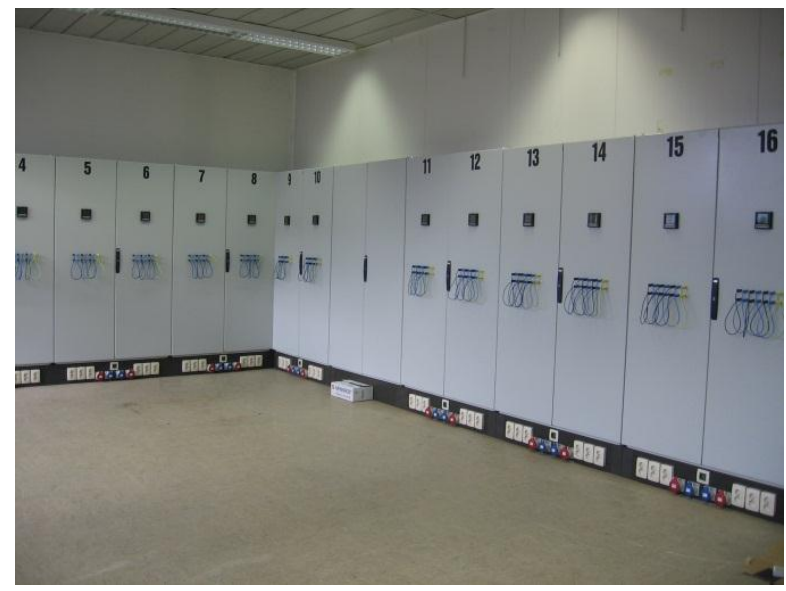

Fig. 5: general overview of the actual test facility

\section{FUTURE EXPANSION}

However several expansions are planned to even further increase the flexibility and research possibilities.

Seventeen programmable loads of $4 \mathrm{~kW}$ each will be installed, while 1 installation is already fully equipped with real residential loads. In addition, a free programmable induction generator representing a Small Wind Turbine and a synchronous generator representing a CHP of 50kVA electric power are planned to be interfaced to the grid.

A smaller but actual $\mu \mathrm{CHP}$ of $26 \mathrm{~kW}$ thermal power and $1 \mathrm{~kW}$ electrical output power has already been purchased, and is to be integrated within the grid.

Both the rise of electrical vehicles, as the growing concern of short term outages has resulted in an increased interest towards local storage. However, it is believed that the integration of storage can also result in new opportunities for the DNO as storage can result in decongestion of the distribution grid. Therefore electrical charging points for electrical vehicles are already integrated, as is local storage envisioned.

\section{RESEARCH OPPORTUNITIES}

The proposed grid is already up and running and is in fine tuning stage. It enables a fast, reconfigurable and controllable tool with individual monitoring of each node.

Although this paper mainly focusses on the design of the test facility, no test bed has ever been built without a clear research vision. Some of the intended research topics are:

1. The increase of "high" frequent harmonics $(>2 \mathrm{kHz})$, mainly caused by Switch Mode Power Supplies, are known to cause actual problems, such as correct metering. [3] - [8]

2. The integration of smart meters and the planned deployment of smart (micro)grids. A lot of simulation has been executed, although practical validation of these simulations should be executed. [9] [10]

3. The massive implementation of DG, possible storage equipment, DSM etc. also impose additional stress to the grid. [11]

The previous does indicate some of the research topic initiated by the authors. However this paper is also an open invitation to third parties for collaborated research.

\section{ACKNOWLEDGMENTS}

This test setup would not have been possible without a lot of funding and support. Consequently, the authors wish to thank the Flemish Hercules foundation for granting the programmable power source of $240 \mathrm{kVA}$ used as grid simulator. A word of appreciation also goes to the EFRO Funding for financial support for the necessary investments. And last but not least, a word of gratitude to all partners, both industrial as distribution grid operators, for supplying the grid, tools and the equipment.

\section{REFERENCES}

[1] Surya Santoso, Mark F. McGranaghan, Roger C. Dugan, H. Wayne Beaty Electrical Power Systems Quality, Third Edition ISBN: 9780071761550

[2] NF C15-100: Coordination des travaux sur les installations a basse tension. 2002.

[3] J. Meyer et al., "Power quality challenges in future distribution networks," in IEEE PES Innovative Smart Grid Technologies Europe Conference, Manchester, 
U.K., 2011.

[4] S. K. Rönnberg et al., "Measurements of interaction between equipment in the frequency range 9 to 95 $\mathrm{kHz}, "$ In International Conference on Electricity Distribution, Prague, Czech Republic, 2009.

[5] J.H.R. Enslin, W.T.J. Hulshorst, J.F. Groeman, A.M.S. Atmadji, P.J.M. Heskes: "Harmonic Interaction between Large Numbers of Photovoltaic Inverters and the Distribution Network", IEEE Power Tech Conference, Italy, June 2003.

[6] P. Khamphakdi et al., "The conducted electromagnetic interference of small grid connected inverter to power system," in IEEE $17^{\text {th }}$ International Symposium on Electromagnetic Compatibility, Zurich, Switzerland, 2006.

[7] S. K. Rönnberg et al., "Total conducted emission from a customer in the frequency range 2 to $150 \mathrm{kHz}$ with different types of lighting," in CIRED $21^{\text {st }}$ International Conference on Electricity Distribution, Frankfurt, Germany, 2011.

[8] S. K. Rönnberg et al., "Measurements of interaction between equipment in the frequency range 9 to 95 $\mathrm{kHz}$," In International Conference on Electricity Distribution, Prague, Czech Republic, 2009.

[9] T.L. Vandoorn, B. Meersman, L. Degroote, B. Renders and L. Vandevelde, “A Control Strategy for Islanded Microgrids with dc-link Voltage Control", in IEEE Trans. Power Del., Volume: 26 Issue: 2 Pages: 703-713, Apr. 2011

[10] T.L. Vandoorn, B. Renders, L. Degroote, B. Meersman and L. Vandevelde, “Active Load Control in Islanded Microgrids based on the Grid Voltage", in IEEE Trans. on Smart Grid, Volume: 2 Issue: 1 Pages: 127-139, March 2011

[11] Debruyne, C., Vanalme, J., Verhelst, B., Desmet, J., Capelle, J. \& Vandevelde, L. (2011). "Preventing overvoltages in $P V$ grids by integration of small storage capacity." In: 2nd European conference and exhibition on Innovative Smart Grid Technologies (IEEE-ISGT-EUROPE 2011), Manchester, UK, 201112-05.

[12] http://www.phasetophase.nl/pdf/StochastischeLoadflowToepassing.pdf (Only available in dutch) 